\title{
Factors associated with obesity among Korean adolescents
}

\author{
Gyu Jin Heo, So Young Nam, Soo-Kyung Lee* \\ Department of Food and Nutrition, Inha University, Incheon, Korea; ${ }^{*}$ Corresponding Author: skleenutrition@inha.ac.kr \\ Received 15 June 2013; revised 16 July 2013; accepted 31 July 2013 \\ Copyright (C) 2013 Gyu Jin Heo et al. This is an open access article distributed under the Creative Commons Attribution License, \\ which permits unrestricted use, distribution, and reproduction in any medium, provided the original work is properly cited.
}

\section{ABSTRACT}

Obesity has been a great interest of public health. Studies simultaneously examining various factors associated with obesity among adolescents have been limited. Therefore, this study aimed to examine how various factors (socioeconomic status, sex, age, diet, and physical activity) were simultaneously associated with obesity among Korean adolescents. This study analyzed two nationally representative datasets: 2008 Korea National Health and Nutrition Examination and Survey (KNHANES) and 2008 Korea Youth Risk Behavior Web-based Survey (KYRBWS). A total of 900 adolescents (12 - 18 year-old) in KNHANES and 74,451 adolescents in KYRBWS were included in statistical analyses with SPSS 19.0. Overweight (5.7\%) and obesity $(13.9 \%)$ rates were determined in KNHANES, and KYRBWS showed somewhat lower rates. No significant associations between the various factors and obesity were found in KNHANES. However, the analysis of KYRBWS confirmed higher obesity risk for boys, lower economic status, inferquent high-energy/low-nutrient type food consumption, practicing moderate-intensity physical activity less than five days per week, spending more than 2 hours sitting per day, and having tried exercise or diet for weight control $(p<0.05)$. The results from the two national datasets seemed to generally agree that many of the various obesity risk factors were important among Korean adolescents, although the associations were mostly not significant in KNHANES. It seemed that obese adolescents tried to practice good dietary behaviors, but not necessarily physical activity, known to reduce obesity risk. Obesity policies should continue to help adolescents achieve an active lifestyle and healthy eating behaviors.

Keywords: Obesity; Risk Factors; Korea; Adolescent

\section{INTRODUCTION}

Recent modernization and globalization have led to lower physical activity and higher energy consumption, resulting in increased obesity rates around the world [1]. Children and adolescents are not exceptions. Child and adolescent obesity rates have almost doubled from 5.8\% in 1997 to $9.7 \%$ in 2005 in Korea [2]. Many factors, including socioeconomic status (SES), sex, age, dietary habits, physical activity, and other lifestyle factors, have been studied in relation to child and adolescent obesity. SES appears to have a positive relationship with obesity in developing countries, whereas a negative relationship in developed countries [3-6]. Further, boys and older age people are positively associated with obesity $[7,8]$. The relationships between sex, age, and obesity may differ by country. Dietary habits providing higher level and easily usable form of energy have been studied. For example, consumption of high-energy/low-nutrient foods, beverages, and fast food and habits of overeating have been previously researched [7-12]. Physical activity has been studied in the context of physical activity for leisure and physical activity for daily activities [10,13-15]. These various factors have been simultaneously examined in a comprehensive manner in only a few studies. In addition, adolescents have received less attention relative to children, despite adolescence constituting an important life stage connecting childhood to adulthood [16].

This study aimed to examine association patterns between various factors (SES, sex, age, diet, and physical activity) and obesity among Korean adolescents using Korea National Health and Nutrition Examination Survey (KNHANES) and Korea Youth Risk Behavior Webbased Survey (KYRBWS). These datasets are two ma- 
jor nationally representative data sources in Korea, each with its own strengths and weaknesses. Therefore, utilizing the two datasets simultaneously would provide a comprehensive breakdown of the current status of obesity-related factors among Korean adolescents.

\section{METHODS}

\subsection{Subjects}

This study used 2008 KNHANES [17] and KYRBWS [18]. KNHANES is a national survey of health behaviors and medical status of Koreans of all ages. Variables are directly measured or obtained by personal interviews. KYRBWS is an online survey focused on health behaviors among students in middle-high and high schools. All variables are self-reported, but the number of participants is very large, affording higher statistical power.

Analyses were conducted with a total of 900 adolescents ( 472 boys and 428 girls) aged between 12 and 18 in 2008 KNHANES and 74,451 adolescents (38,795 boys and 35,656 girls) in 2008 KYRBWS. Age was dichotomized: 12 - 15 (middle-high school) and 16 - 18 (high school) years old.

\subsection{Study Variables}

1) Body weight status

Body Mass Index (BMI) in KNHANES was calculated from directly measured height and weight, while BMI in KYRBWS was calculated from self-reported ones. Adolescents with a BMI over 95th percentile or over 25 were determined to be obese; adolescents with a BMI between $85^{\text {th }}$ and $95^{\text {th }}$ percentile were determined to be overweight. Adolescents with a BMI below $5^{\text {th }}$ percentile were categorized as underweight and others as normal weight [19].

2) Obesity-related factors

a) Socioeconomic status

SES were determined based on monthly household income adjusted for the number of family members, parents' occupation, and parents' education in KNHANES, while parents' education and economic status in KYRBWS were used to determine SES. Monthly household income in KNHANES was re-categorized into two groups: individuals with incomes below $120 \%$ of the Korea poverty level [20] ort hose with incomes above the level. KYR BWS provided parents' economic status as: 1) low, 2) middle-low, 3 ) middle, 4) middle-high, or 5) high. Parents' education was dichotomized into: 1) lower than high school graduation, or 2) high school graduation and higher. Parents' occupation, available only in KNHA NES, was dichotomized into: 1) currently working, or 2) currently not working.

b) Dietary factors
Dietary factors included: 1) high-energy/low-nutrient (HELN) food consumption, and 2) energy consumption level. High-energy/low-nutrient foods are energy-dense foods with a minimal level of nutrients, and a list of such foods are monthly published by the Korea Food and Drug Administration [21]. In KNHANES, consumption of high-energy/low-nutrient foods such as instant noodles, bread, cookies, ice cream, carbonated drinks, hamburgers, pizza, and fried foods was dichotomized into infrequent or frequent users. Adolescents who consumed five or more HELN food items once a week or more were grouped as frequent users; adolescents who consumed-four or less food items once a week or more were grouped as infrequent users. KYRBWS asked the consumption frequency of carbonated drinks, instant noodles, fast food, and cookies. Adolescents in KYRBWS were also re-categorized as 1) infrequent users (those who answered the "do not eat" category), or 2) frequent users (those who answered any of the other categories).

Energy consumption level was determined by comparing energy intake from 24-hr recalls with individually estimated energy requirement, calculated using the formulas in the 2010 Dietary Reference Intakes for Koreans [22]. Energy consumption level was examined only in KNHANES, as KYRBWS did not conduct 24-hr recalls.

c) Physical activity factors

Physical activity factors included: 1) vigorous- intensity activity, 2) moderate-intensity activity, 3) walking, 4) sedentary hours, and 5) sleeping hours.

Vigorous-intensity activity for 20 minutes or more per session is recommended three days or more per week. Moderate-intensity activity for 30 minutes or more per session is recommended five days or more per week. Walking for 30 minutes or more per session is recommended five days or more per week [17,23]. Subjects were categorized as those who met or those who did not meet the recommendation for each physical activity factors.

Sedentary hours were provided only in KYRBWS. Following the Dietary Guidelines for Korean Adolescents [24], individuals were grouped into two categories: 1) 2 hours per day or more or 2) less than 2 hours. "Sleeping hours" was also dichotomized into 1) less than 7 hours per day or 2) 7 hours or more per day.

d) Controlling factors

Whether or not adolescents attempted exercise or dietary means (e.g. eating less, fast, etc.) for weight control was asked in KNHANES and KYRBWS. Subjects were categorized as 1) those who attempted or 2) those who did not.

\subsection{Statistical Analysis}

This study used statistical analysis methods reflecting 
the complex sample survey design of KNHANES and KYRBWS, using SPSS 19.0 (IBM SPSS, Armonk, NY, USA).

Basic descriptive methods were used to determine the status of the study variables, whereas logistic regression analyses were used to examine relationships among the variables. The relationships between obesity and risk factors were examined in a series of multiple logistic regression models: Model I (SES variables), Model II (sex, age, dietary variables, and the controlling variable), Model III (sex, age, physical activity variables, and the controlling variable), and Model IV. When significant relationships were found in previous models, model IV was established including all study variables.

\section{RESULTS}

\subsection{Obesity Status}

Overweight or obesity rate among 12 - 18 year-old adolescents in KNHANES was 19.6\%, whereas KYRBWS showed a lower rate of $11.8 \%$. Boys showed a higheroverweight or obesity rate $(22.3 \%$ in KNHANES, 13.3 in KYRBWS) than girls (16.5\% in KNHANES, 10.2 in KYRBWS). While more boys were obese than overweight, more girls were overweight than obese $(p<0.05)$. The two datasets indicated that older (16 - 18 year-old) adolescents tented to be more obese than younger (12 15 year-old) ones (Table 1).

\subsection{Obesity-Related Factors in KNHANES}

No significant associations were found in Model I and II (Table 2). Model III found that girls $(\mathrm{OR}=0.36)$ were less likely to be overweight or obese $(p<0.05)$. Since separate analyses did not show consistent statistically significant relationships, Model IV was not established.

\subsection{Obesity-Related Factors in KYRBWS}

According to Model I in Table 3, economic level was negatively related to obesity. Compared to adolescents who reported a low SES level, those who reported a higher SES level were less likely to be obese. Model II indicated that obesity probability was higher for less frequently consuming fast food $(\mathrm{OR}=0.78)$, ramen $(\mathrm{OR}$ $=0.90)$, or snacks $(\mathrm{OR}=0.74)$, and having dieted for weight control $(\mathrm{OR}=4.25)$. Model III showed that moderate-intensity active adolescents $(\mathrm{OR}=0.88)$ were less likely to be obese, whereas adolescents who were more sedentary during weekdays $(\mathrm{OR}=1.11)$ or weekends $(\mathrm{OR}=1.23)$ and exercised for weight control $(\mathrm{OR}=1.13)$ were more likely to be obese.

Most of the significant factors in the previous models remained significant in the full model, Model IV. Higher obesity probability were found for lower economic status, infrequent high-energy/low-nutrient food consumption, vigorous-intensity active, moderate-intensity inactive, spending more than 2 hours a day sitting, and having tried

Table 1. Prevalence of overweight and obesity among Korean adolescents by sex and age. \%(SE) ${ }^{1)}$.

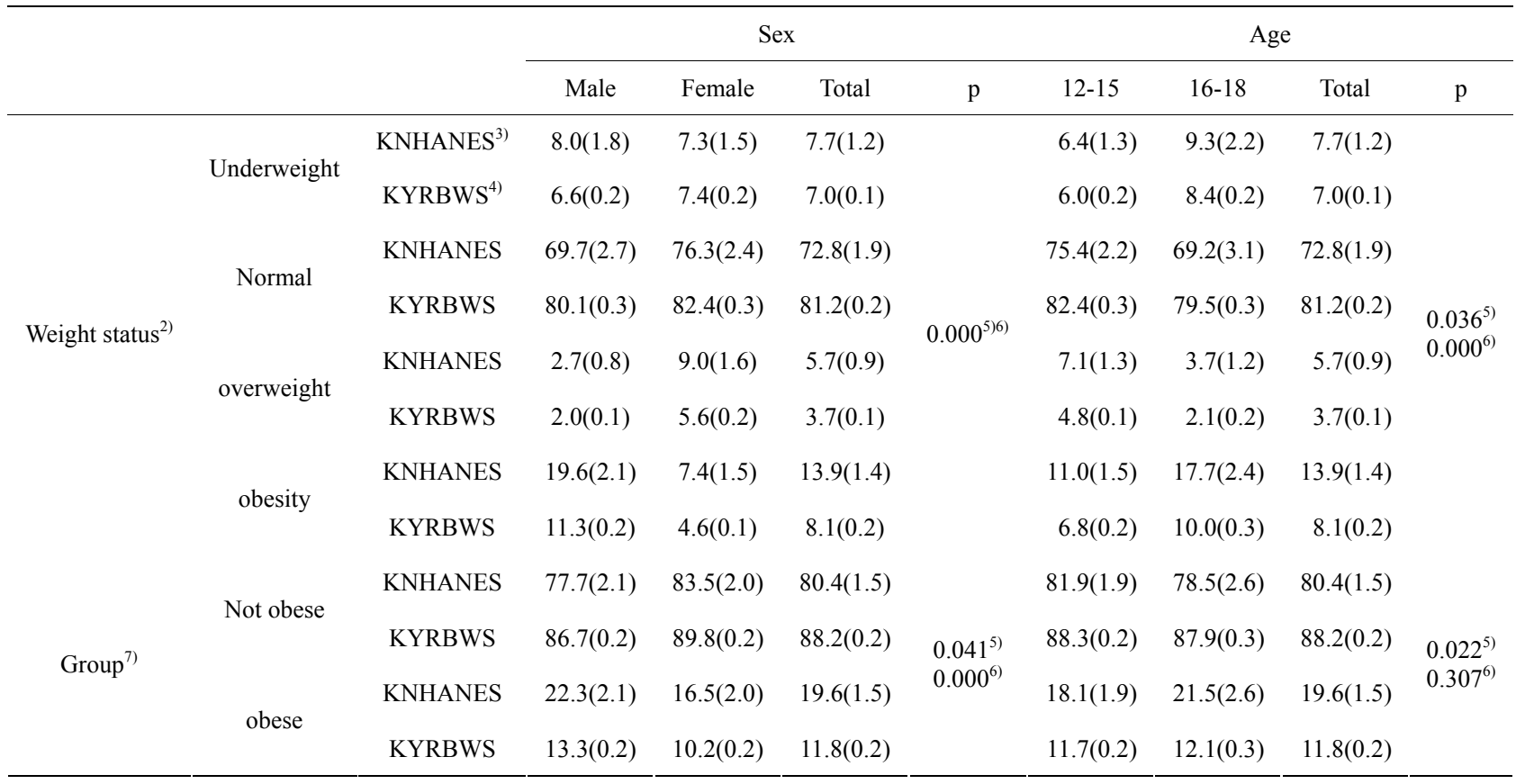

${ }^{1)}$ Estimated percentage of population(standard error); ${ }^{2} 2007$ Korean National Growth Charts. Underweight: $<5^{\text {th }}$ percentile, Normal: $5^{\text {th }}-85^{\text {th }}$ percentile, Overweight: $85^{\text {th }}-95^{\text {th }}$ percentile, Obesity: $\geq 95^{\text {th }}$ percentile or $\geq$ BMI $25 ;{ }^{3)}$ Korea National Health and Nutrition Examination Survey; ${ }^{4)}$ Korea Youth Risk Behavior Web-based Survey; ${ }^{5}$ Sex or age difference of KNHANES; ${ }^{6}$ Sex or age difference of KYRBWS; ${ }^{7)}$ Not obese (underweight + normal), Obese (overweight +obese). 
Table 2. Relationships between risk factors and overweight and obesity in 2008 Korea National Health and Nutrition Examination Survey. OR $(95 \% \mathrm{CI})^{1)}$.

\begin{tabular}{|c|c|c|c|c|}
\hline & & Model I $(\mathrm{N}=505)$ & Model II $(\mathrm{N}=335)$ & Model III $(\mathrm{N}=404)$ \\
\hline \multirow[t]{2}{*}{ Sex } & Male & 1.00 & 1.00 & 1.00 \\
\hline & Female & $0.93(0.56,1.56)$ & $0.34(0.20,0.58)$ & $0.36(0.22,0.59)$ \\
\hline \multirow[t]{2}{*}{ Age } & $12-15$ years & 1.00 & 1.00 & 1.00 \\
\hline & $16-18$ years & $1.50(0.89,2.52)$ & $1.11(0.59,2.08)$ & $0.92(0.52,1.60)$ \\
\hline \multicolumn{5}{|l|}{ Socioeconomic factors } \\
\hline \multirow{2}{*}{ Income compared with the minimum cost of living } & $<120 \%$ & 1.00 & & \\
\hline & $\geq 120 \%$ & $0.90(0.41,1.96)$ & & \\
\hline \multirow[t]{2}{*}{ Father's education } & $\leq$ high school & 1.00 & & \\
\hline & $\geq$ high school & $1.32(0.62,2.82)$ & & \\
\hline \multirow[t]{2}{*}{ Mother's education } & $\leq$ high school & 1.00 & & \\
\hline & $\geq$ high school & $0.98(0.44,2.16)$ & & \\
\hline \multirow[t]{2}{*}{ Father's occupation } & Not & 1.00 & & \\
\hline & Working & $0.96(0.31,2.97)$ & & \\
\hline \multirow[t]{2}{*}{ Mother's occupation } & Not & 1.00 & & \\
\hline & Working & $1.29(0.71,2.34)$ & & \\
\hline \multicolumn{5}{|l|}{ Dietary factors } \\
\hline \multirow{2}{*}{ The proportion of energy by $\mathrm{EER}^{2)}$} & $<100 \%$ & & 1.00 & \\
\hline & $\geq 100 \%$ & & $0.57(0.29,1.15)$ & \\
\hline \multirow{2}{*}{ Intake of High energy/ Low nutrient food types } & Infrequent ${ }^{6)}$ & & 1.00 & \\
\hline & Frequent & & $0.96(0.56,1.63)$ & \\
\hline \multirow{2}{*}{ Weight control by fast, diet, and others } & Not attempt & & 1.00 & \\
\hline & Attempt & & $1.39(0.86,2.25)$ & \\
\hline \multicolumn{5}{|l|}{ Physical activity } \\
\hline \multirow{2}{*}{ Vigorous-intensity activities ${ }^{3)}$} & $<3$ days & & & 1.00 \\
\hline & $\geq 3$ days & & & $1.08(0.50,2.36)$ \\
\hline \multirow{2}{*}{ Moderate-intensity activities ${ }^{4)}$} & $<5$ days & & & 1.00 \\
\hline & $\geq 5$ days & & & $1.01(0.43,2.36)$ \\
\hline \multirow[t]{2}{*}{ Walking ${ }^{5)}$} & $<30 \min$ & & & 1.00 \\
\hline & $\geq 30 \mathrm{~min}$ & & & $1.10(0.68,1.78)$ \\
\hline \multirow[t]{2}{*}{ Sleeping time } & $<7$ hours & & & 1.00 \\
\hline & $\geq 7$ hours & & & $0.72(0.40,1.30)$ \\
\hline \multirow{2}{*}{ Weight control by exercise } & Not attempt & & & 1.00 \\
\hline & Attempt & & & $1.22(0.63,2.35)$ \\
\hline $\begin{array}{l}\text { Dependent variable: Obese (overweight }+ \text { obese), Not } \\
\text { Energy Requirement; 3) Vigorous-intensity activities: } \\
\text { last week; 4) Moderate-intensity activities: having exerc } \\
\text { Walking: walked } 30 \text { minutes or more per session, five d } \\
\text { fewer than five items from ramen, bread, cookies, ice } \\
\text {-consumed five items or more. }\end{array}$ & $\begin{array}{l}\text { nderweight }+ \text { no } \\
\text { xercised with vig } \\
\text { h moderate-inten } \\
\text { week or more, } 1 \\
\text { soft drink, ham }\end{array}$ & $\begin{array}{l}\text { al): Reference } 1 \text { ) Odd } \\
\text { ous-intensity } 20 \text { minut } \\
\text { y } 30 \text { minutes or more } p \\
\text { week; } 6 \text { ) High-energy/ } \\
\text { rger, pizza, and fried }\end{array}$ & $\begin{array}{l}\text { atio }(95 \% \text { confidence } \\
\text { or more per session, } \\
\text { session, three days pe } \\
\text { W-nutrient food types: } \\
\text { od more often than o }\end{array}$ & $\begin{array}{l}\text { erval); 2) EER: Estimate } \\
\text { e days per week or mor } \\
\text { eek or more, last week; } \\
\text { requent users - consume } \\
\text { per week; Frequent us }\end{array}$ \\
\hline
\end{tabular}


Table 3. Relationship between risk factors and overweight and obesity in 2008 Korea Youth Risk Behavior Web-based Survey. OR $(95 \% \mathrm{CI})^{1)}$.

\begin{tabular}{|c|c|c|c|c|c|}
\hline & & Model I $(\mathrm{N}=55,099)$ & Model II $(\mathrm{N}=33,327)$ & Model III $(\mathrm{N}=33,327)$ & Model IV $(\mathrm{N}=25,409)$ \\
\hline \multirow[t]{2}{*}{ Sex } & Male & 1.00 & 1.00 & 1.00 & 1.00 \\
\hline & Female & $0.72(0.67,0.77)$ & $0.42(0.39,0.46)$ & $0.67(0.61,0.72)$ & $0.41(0.37,4.58)$ \\
\hline \multirow[t]{2}{*}{ Age } & $12-15$ years & 1.00 & 1.00 & 1.00 & 1.00 \\
\hline & $16-18$ years & $1.02(0.95,1.01)$ & $0.92(0.85,0.99)$ & $0.98(0.90,1.06)$ & $0.95(0.86,1.05)$ \\
\hline \multicolumn{6}{|l|}{ Socioeconomic factors } \\
\hline \multirow[t]{2}{*}{ Father's education } & $\leq$ high school & 1.00 & & & 1.00 \\
\hline & $\geq$ high school & $1.06(0.94,1.21)$ & & & $1.19(1.00,1.42)$ \\
\hline \multirow[t]{2}{*}{ Mother's education } & $\leq$ high school & 1.00 & & & 1.00 \\
\hline & $\geq$ high school & $0.95(0.81,1.11)$ & & & $0.89(0.73,1.08)$ \\
\hline \multirow[t]{5}{*}{ Economic level } & Low & 1.00 & & & 1.00 \\
\hline & Middle low & $0.88(0.75,1.02)$ & & & $0.81(0.66,1.00)$ \\
\hline & Middle & $0.69(0.59,0.80)$ & & & $0.73(0.60,0.88)$ \\
\hline & High middle & $0.72(0.62,0.84)$ & & & $0.77(0.63,0.93)$ \\
\hline & High & $0.74(0.61,0.89)$ & & & $0.74(0.57,0.95)$ \\
\hline \multicolumn{6}{|l|}{ Dietary factors } \\
\hline \multirow{2}{*}{ Frequency of fast food intake } & Infrequent $\left.{ }^{6}\right)$ & & 1.00 & & 1.00 \\
\hline & Frequent & & $0.78(0.72,0.84)$ & & $0.79(0.72,0.86)$ \\
\hline \multirow{2}{*}{$\begin{array}{l}\text { Frequency of carbonated } \\
\text { ldrink intake }\end{array}$} & Infrequent & & 1.00 & & 1.00 \\
\hline & Frequent & & $0.93(0.87,1.00)$ & & $0.92(0.84,1.00)$ \\
\hline \multirow[t]{2}{*}{ Frequency of ramen intake } & Infrequent & & 1.00 & & 1.00 \\
\hline & Frequent & & $0.90(0.84,0.98)$ & & $0.89(0.81,0.97)$ \\
\hline \multirow[t]{2}{*}{ Frequency of snacks intake } & Infrequent & & 1.00 & & 1.00 \\
\hline & Frequent & & $0.73(0.67,0.81)$ & & $0.74(0.66,0.82)$ \\
\hline \multirow{2}{*}{$\begin{array}{l}\text { Weight control by fast, } \\
\text { diet, and others }\end{array}$} & Not attempt & & 1.00 & & 1.00 \\
\hline & Attempt & & $4.25(3.86,4.69)$ & & $4.31(3.85,4.82)$ \\
\hline \multicolumn{6}{|l|}{ Physical activity } \\
\hline \multirow{2}{*}{$\begin{array}{l}\text { Vigorous-intensity } \\
\text { activities }^{2)}\end{array}$} & $<3$ days & & & 1.00 & 1.00 \\
\hline & $\geq 3$ days & & & $1.08(1.00,1.18)$ & $1.15(1.05,1.26)$ \\
\hline \multirow{2}{*}{$\begin{array}{l}\text { Moderate-intensity } \\
\text { activities }^{3)}\end{array}$} & $<5$ days & & & 1.00 & 1.00 \\
\hline & $\geq 5$ days & & & $0.88(0.79,0.99)$ & $0.84(0.74,0.96)$ \\
\hline \multirow{2}{*}{$\begin{array}{l}\text { Walking }^{4} \text { ) } \\
\text { (weekday, per day) }\end{array}$} & $<30 \min$ & & & 1.00 & 1.00 \\
\hline & $\geq 30 \mathrm{~min}$ & & & $1.03(0.93,1.14)$ & $1.06(0.94,1.20)$ \\
\hline \multirow{2}{*}{$\begin{array}{l}\text { Walking } \\
\text { (weekend, per day) }\end{array}$} & $<30 \min$ & & & 1.00 & 1.00 \\
\hline & $\geq 30 \mathrm{~min}$ & & & $1.00(0.91,1.10)$ & $1.04(0.93,1.15)$ \\
\hline \multirow{2}{*}{$\begin{array}{l}\text { Sedentary hours }{ }^{5} \\
\text { (weekday, per day) }\end{array}$} & $<2$ hours & & & 1.00 & 1.00 \\
\hline & $\geq 2$ hours & & & $1.11(1.03,1.19)$ & $1.12(1.03,1.22)$ \\
\hline \multirow{2}{*}{$\begin{array}{l}\text { Sedentary hours } \\
\text { (weekend, per day) }\end{array}$} & $<2$ hours & & & 1.00 & 1.00 \\
\hline & $\geq 2$ hours & & & $1.23(1.12,1.34)$ & $1.22(1.10,1.36)$ \\
\hline \multirow[t]{2}{*}{ Sleeping time } & $<7$ hours & & & 1.00 & 1.00 \\
\hline & $\geq 7$ hours & & & $1.02(0.94,1.11)$ & $1.11(1.00,1.24)$ \\
\hline \multirow{2}{*}{ Weight control by exercise } & Not attempt & & & 1.00 & 1.00 \\
\hline & Attempt & & & $1.13(1.05,1.22)$ & $1.11(1.01,1.21)$ \\
\hline
\end{tabular}

Dependent variable: Obese (overweight + obese), Not obese (underweight + normal): Reference 1) Odds ratio (95\% confidence interval); 2 ) Vigorous-intensity activities: 20 minutes per session or more, last week; 3) Moderate-intensity activities: 30 minutes per session or more, last week; 4) Walking: walked 30 minutes or more per session, five days per week or more, last week; 5) Spending time watching TV, playing games, Internet, etc. (exception of watching during school hours, watching of education broadcast, etc.); 6) Infrequent (original response category: rarely); Frequent (original response category: Once 6 - 7 days, Once 4 5 days, Once 2 - 3 days, $\geq$ Once a day). 
exercise or diet for weight control $(\mathrm{p}<0.05)$.

Overall, analyses of KNHANES and KYRBWS resulted in similar trends, although the results from $\mathrm{KNH}$ ANES were not significant.

\subsection{Discussion}

This study attempted a comprehensive and simultaneous analysis on the relationships of socioeconomic, dietary, and physical activity factors with obesity in Korean adolescents using 2008 KNHANES and KYRBWS.

Overweight $(5.7 \%)$ and obesity $(13.9 \%)$ rates among 12 - 18 year-old adolescents in 2008 KNHANES were similar to those from 2007 KNHANES, but slightly higher than those from $2005 \mathrm{KNHANES}[8,17]$. Overweight $(3.7 \%)$ and obesity $(8.1 \%)$ rates from 2008 KYRBWS were also similar to those from 2007 KYRBWS [19,25]. Therefore, recent overweight and obesity rates among Korean adolescents have appeared to plateau in general.

Girls were less likely to be obese than boys. Girls showed higher overweight rates, whereas boys displayed higher obesity rates. This trend was also observed in 2007 KNHANES, the National Youth Policy Institute report on child/adolescent obesity, and the 2009 student health check by the Ministry of Education, Science, and Technology $[8,15,26]$. Therefore, obesity prevention policies and programs should provide more care for boys.

This study found that overweight and obesity prevalence was lower in KYRBWS compared to KNHANES. This discrepancy seems largely due to different data collection methods. KNHANES used direct measurement methods, whereas KYRBWS used self-reported data. If statistical methods to adjust for this discrepancy can be devised, national data on obesity could be better managed and utilized.

The KYRBWS results showed that adolescents at lower quintiles of economic level were at higher risk for overweight and obesity. No significant relationships between SES and obesity were found in KNHANES, possibly because of the low statistical power. Perhaps, subjectively measured economic status could influence body weight status more than objectively measured economic status [27]. The nature of relationships between SES and obesity in Korea would be of great interest to the international community as Korea has been and still is transitioning from a developing to developed economy in such a dynamic fashion.

Examination of dietary factors showed that high-energy/low-nutrient foods were less likely to be consumed by obese children. This finding could be attributed to the cross-sectional nature of the datasets used in this study. That is, obese adolescents tend to stay away from snacks $[10,14]$. Adolescents seem to know which foods are better for weight control, and obese adolescents seem to put the knowledge into practice. Although this is an encour- aging sign, public health efforts should be continued to lower consumption of such high-energy/low-nutrient foods [28,29].

This study showed that adolescents who spent more than 2 hours sitting per day were more likely to be obese. However, relationships between exercise and obesity differ by intensity. These results seemed to indicate that although obese adolescents had a more sedentary lifestyle, they tried vigorous-intensity activities more often, but not moderate-intensity activities. Therefore, obesity prevention for adolescents should include policy and environments supporting both an active lifestyle (i.e. spending less time watching TV or internet) and more exercise (i.e. increasing physical education class hours, promoting group sports for fun) [28,29].

This study was limited by being unable to statistically compare the two datasets, as different sampling strategies and measurement methods were used. Making causal inferences was also difficult because of the crosssectional nature of the datasets. Further, KNHANES may lack sufficient statistical power because of the low number of participants. Large-scale cohort studies on obesity among children and adolescents would be able to provide much of the needed missing information for obesityrelated research and policy-making.

This study is one of a few that has simultaneously examined various factors associated with obesity utilizing two nationally representative datasets collected through different sampling and measurement methods. The results from the two national datasets seemed to generally indicate that obese adolescents tried to actively practicegood dietary behaviors, but not necessarily physical activity, known to reduce obesity risk. Therefore, obesity prevention policies should continue to help adolescents achieve an active lifestyle and healthy eating habits.

\section{ACKNOWLEDGEMENTS}

This research was supported by an Inha University grant.

\section{REFERENCES}

[1] Swinburn, B.A., Sack, G., Hall, K.D., McPherson, K., Finefood, D.T., Moodle, M.L. and Gortmaker, S.L. (2011) The global obesity pandemic: Shaped by global drivers and local environments. Lancet, 378, 804-814. doi:10.1016/S0140-6736(11)60813-1

[2] Oh, K.W., Jang, M.J., Lee, N.Y., Moon, J.S., Lee, C.G., Yoo, M.H. and Kim, Y.T. (2008) Prevalence and trends in obesity among korean children and adolescents in 1997 and 2005. Korean Journal of Pediatrics, 51, 950-955. doi:10.3345/kjp.2008.51.9.950

[3] Stamatakis, E., Wardle, J. and Cole, T.J. (2010) Childhood obesity and overweight prevalence trends in England: Evidence for growing socioeconomic disparities. International Journal of Obesity, 34, 41-47. 
doi:10.1038/ijo.2009.217

[4] Lioret, S., Touvier, M., Dubuisson, C., Dufour, A., Calamassi-Tran, G., Lafay, L., Volatier, J.L. and Maire, B. (2008) Trends in child overweight rates and energy intake in France from 1999 to 2007: Relationships with socioeconomic status," Obesity, 17, 1092-1100. doi:10.1038/oby.2008.619

[5] Shrewsbury, V. and Wardle, J. (2008) Socioeconomic status and adiposity in childhood: A systematic review of cross-sectional studies 1990-2005. Obesity, 16, 275-284. doi:10.1038/oby.2007.35

[6] Kinra, S., Nelder, R.P. and Lewendon, G.J. (2000) Deprivation and childhood obesity: A cross sectional study of 20,973 children in Plymouth, United Kingdom. Journal of Epidemiology \& Community Health, 54, 456-460. doi:10.1136/jech.54.6.456

[7] Ogden, C.L., Yanovski, S.Z., Carroll, M.D. and Flegal, K.M. (2007) The epidemiology of obesity. Gastroenterology, 132, 2087-2102.

doi:10.1053/j.gastro.2007.03.052

[8] Ministry of Health and Welfare and family Affairs, Korea Centers for Disease Control and Prevention (2008) 2007 national health statistics. 4th Korea national health and nutrition examination survey. KCDC, Seoul.

[9] Park, M.A., Moon, H.K., Lee, K.H. and Suh, S.J. (1998) A study on related risk factors of obesity for primary school children: Difference between normal and obese group. Korean Journal of Nutrition, 31, 1158-1164.

[10] Baek, S.H. (2009) Do obese children exhibit distinguishable behaviors from normal weight children-based on literature review. Korean Journal of Community Nutrition, 13, 386-395.

[11] Malik, V.S., Schulze, M.B. and Hu, F.B. (2006) Intake of sugar-sweetened beverages and weight gain: A systematic review. American Journal of Clinical Nutrition, 84, 274288.

[12] Moreno, L.A. and Rodriguez, G. (2007) Dietary risk factors for development of childhood obesity. Current Opinion in Clinical Nutrition \& Metabolic Care, 10, 336-341. doi:10.1097/MCO.0b013e3280a94f59

[13] Kleiser, C., Rosario, A.S., Mensink, G.B., Prinz-Langenohl, R. and Kurth, B.M. (2009) Potential determinants of obesity among children and adolescents in Germany: Results from the cross-sectional KiGGS study. BMC Public Health, 9. doi:10.1186/1471-2458-9-46

[14] Baek, S.H. and Yeo, J.H. (2006) Comparison of weight control behavior and self-esteem between healthy weight and obese children. Korean Journal of Community Nutri- tion, 11, 562-574.

[15] H.J. Lim, H.R. Park and H.K. Koo (2009) Research on obesity status among children and adolescent and policy. Education Center Report (\#09-R10), National Youth Policy Institute, Seoul, 87-174.

[16] Mitchell, M.K. (2003) Nutrition across the life span. W.B. Saunders Co., Philadelphia.

[17] Korea Centers for Disease Control and Prevention (2008) The fourth korea national health and nutrition examination survey (KNHANES VI), 2008. KCDC, Seoul.

[18] Ministry of Health and Welfare and Family Affairs, Korea Centers for Disease Control and Prevention, Ministry of Education, Science and Technology (2008) 2008 Korea youth risk behavior web-based survey. MHWFA, Seoul.

[19] Korea Center for Disease Control and Prevention, The Korean Pediatric Society (2007) 2007 Korean national growth charts. KCDC, Seoul.

[20] Ministry of Health and Welfare (2010) Ministry of health and welfare year book 2010. MHW, Seoul.

[21] Korea Food and Drug Administration (2010) List of highenergy/low-nutrient foods. KFDA, Seoul.

[22] The Korean Nutrition Society (2005) Dietary reference intakes for Koreans. KNS, Seoul.

[23] US Department of Health and Human Service (2008) 2008 physical activity guideline for Americans summary. USDHHS, Washington DC.

[24] Ministry of Health and Welfare and Family Affairs (2009) Dietary guidelines for Koreans. MHWFA, Seoul.

[25] Ministry of Health and Welfare and Family Affairs, Korea Centers for Disease Control and Prevention, Ministry of Education, Science and Technology (2008) 2007 Korea youth risk behavior web-based survey. MHWFA, Seoul.

[26] Ministry of Education, Science and Technology, Korean Educational Development Institute (2010) 2009 student health check. MEST, Seoul.

[27] Oh, I.H., Cho, Y., Park, S.Y., Oh, C., Choe, B.K., Choi, J.M., et al. (2011) Relationship between socioeconomic variables and obesity in Korean adolescents. Journal of Epidemiology, 21, 263-270. doi:10.2188/jea.JE20100099

[28] World Health Organization (2004) Global strategy on diet, physical activity and health. WHO, Geneva.

[29] Gortmaker, S.L., Swinburn, B.A., Levy, D., Carter, R., Marbry, P.L., Finegood, D.T., Huang, T., Marsh, T. and Moodle, M.L. (2011) Changing the future of obesity: Science, policy, and action. Lancet, 378, 838-847. doi:10.1016/S0140-6736(11)60815-5 